\title{
PENGARUH ASAM STEARAT TERHADAP SIFAT KETEGUHAN PATAH/MODULUS OF RUPTURE PAPAN PARTIKEL TERMOPLASTIK BEKAS BERPENGISI TEMPURUNG KELAPA
}

\author{
Muh. Hendra S Ginting, Rosdanelli Hasibuan \\ Departemen Teknik Kimia Fakultas Teknik, Universitas Sumatera Utara \\ Jl Almamater Kampus USU, Medan 20155, Indonesia \\ Email: hendragtg@yahoo.com
}

\begin{abstract}
Abstrak
Pemanfaatan termoplastik bekas dan tempurung kelapa sebagai papan partikel merupakan salah satu upaya mengurangi limbah plastik pengemas, rasio termoplastik bekas sebagai matriks dan tempurung kelapa sebagai pengisi 60:40. Tujuan penelitian ini adalah untuk mengetahui pengaruh asam stearat terhadap sifat modulus of rupture papan partikel termoplastik bekas berpengisi tempurung kelapa. Metode pembuatan papan partikel ini menggunakan ekstruder, dimulai dengan modifikasi partikel tempurung kelapa (ukuran 80 mesh) dengan asam stearat $\left(0 \mathrm{~g}, 3 \mathrm{~g}, 6 \mathrm{~g}\right.$, dan $9 \mathrm{~g}$ dalam $60 \mathrm{ml}$ etanol) lalu dikeringkan dalam oven pada suhu $70^{\circ} \mathrm{C}$. Matriks dan pengsisi (60:40) dicampurkan dalam ekstruder lalu dicetak dengan pengempa panas pada suhu $170^{\circ} \mathrm{C}$ sehingga terbentuk papan partikel dengan ukuran $200 \mathrm{~mm}$ x $200 \mathrm{~mm}$ x $10 \mathrm{~mm}$. Papan partikel dianalisa sifat keteguhan patah/modulus of rupture sesuai dengan SNI 03-2105-2006. Dari hasil penelitian menunjukkan terjadi peningkatan sifat modulus of rupture. Sifat modulus of rupture terbesar adalah 37,402 MPa.
\end{abstract}

Kata Kunci : termoplastik, ekstruder, asam sterat, tempurung kelapa, papan

\begin{abstract}
The utilization of former thermoplastic and coconut shell as particle board is one way to reduce plastic waste packaging, the ratio of the former as a thermoplastic matrix and coconut shells as fillers 60:40. Purpose of this study was to determine the effect of stearic acid on properties of modulus of rupture former thermoplastic particle board filler of coconut shell. Method of shell particle board manufacturing using the extruder, starting with the modification of coconut shell particles (size $80 \mathrm{mesh}$ ) with stearic acid $(0 \mathrm{~g}, 3 \mathrm{~g}, 6 \mathrm{~g}$ and $9 \mathrm{~g}$ in $60 \mathrm{ml}$ of ethanol) and then dried in an oven at a temperature $70^{\circ} \mathrm{C}$. Matrix and coconut shell (60:40) mixed in the extruder and then printed with hot press at a temperature of $170^{\circ} \mathrm{C}$, until forming particle board with a size of $200 \mathrm{~mm} \times 200 \mathrm{~mm} \times 10$ mm. Particle board analyzed the modulus of rupture in accordance with SNI 03-2105-2006. The results showed an increase in modulus of rupture properties. The modulus of rupture is $37.402 \mathrm{MPa}$ greatest.
\end{abstract}

Keywords : thermoplastic, extruder, stearic acid, coconut shell, particle board

\section{Pendahuluan}

Penggunaan plastik pengemas makanan/ minuman menghasilkan limbah plastik yang sulit dibiodegradasi [2], salah satu upaya untuk meningkatkan nilai plastik pengemas bekas adalah dengan membuat papan partikel berpengisi serat alam $[1,10]$, Serat alam yang digunakan sebagai pengisi misalnya serat nenas, rami padi, kulit salak serbuk tempurung kelapa dan lain-lain [6], Proses pembuatan papan partikel termoplastik berpengisi serat alam, biasanya sulit untuk menghubungkan antara termoplastik sebagai matriks dengan pengisi (serat alam) karena keduanya mempunyai sifat yang berbeda, untuk itu digunakan penyerasi seperti maleat an hidrat, asam akrilat, asam asetat $50 \% \quad[6,8,9]$. Metode yang digunakan pada pembuatan papan partikel diawali dengan modifikasi kimia (proses esterifikasi) pada partikel tempurung kelapa dengan asam stearat yang divariasikan sehingga diharapkan serbuk tempurung kelapa dapat teresterkan.

Tujuan dari penelitian ini adalah untuk mengetahui pengaruh asam stearat terhadap sifat keteguhan patah/modulus of rupture papan partikel termoplastik bekas berpengisi tempurung kelapa $(60 / 40)$

\section{Teori}

Papan partikel adalah papan partikel adalah hasil pengempaan panas campuran partikel kayu atau bahan berlignoselulosa lainnya dengan perekat organik serta bahan lain [1]. Penelitian papan partikel telah banyak dilakukan, diantaranya membuat papan partikel sekam padi dengan ketebalan $1 \mathrm{~cm}, 1,5 \mathrm{~cm}$, dan $2 \mathrm{~cm}$, hasil penelitian didapat sifat isolator panas yang baik adalah dengan ketebalan papan $1 \mathrm{~cm}$ memberikan nilai konduktifitas panas, k sebesar $0.0798 \mathrm{~W} / \mathrm{m} .{ }^{0} \mathrm{C}$ ) [9], papan partikel berbahan baku sabut kelapa dengan bahan pengikat alami (lem kopal), campuran (berat) antara sabut kelapa/lem kopal sebesar 1: 5; 1:6 dengan perbandingan kompresi 4:1.Dari hasil pengujian perbandingan komposisi berat sabut kelapa/kopal yang terbaik adalah 1:6, modulus elastisitas pecah tertinggi sebesar $89,2009 \mathrm{~kg} / \mathrm{mm}^{2}$ pada perbandingan volume kompresi 1:4. Berat 
jenis terbaik terdapat pada komposisi 1:5 dengan nilai berat jenis yaitu $0,58728 \mathrm{~g} / \mathrm{cm}^{3}$ [13].

Kelemahan papan partikel komposit berpengisi serat alami adalah ketidakserasian diantara sifat bahan pengisi yang hidrofilik dengan bahan termoplastik yang bersifat hidrofobik, penghubung termoplastik dan pengisi digunakan lem antara lain urea formaldehid [12], lem kopal [13], Secara urgensi modifikasi serbuk tempurung kelapa dengan asam sterarat $(0 \mathrm{~g}, 3 \mathrm{~g}, 6 \mathrm{~g}$, dan $9 \mathrm{~g}$ masingmasing terlarut dalam $60 \mathrm{ml}$ etanol) sebagai agen penghubung dapat meningkatkan adhesi antar muka serbuk tempurung kelapa dengan matriks termoplastik bekas (40:60) dengan temperatur $170^{\circ} \mathrm{C}$ menghasilkan papan partikel memiliki dan keteguhan patah yang tinggi.

\section{Metodologi Penelitian \\ Bahan Baku}

Bahan baku yang digunakan adalah termoplastik bekas (plastik kemasan cup) sebagaii matriks dan partikel tempurung kelapa sebagai pengisi yang diperoleh disekitar pajak Marelan Pasar V Medan Labuhan.

\section{Prosedur Penelitian}

Tempurung kelapa direndam dengan aquades selama satu jam untuk menghilangkan kotorankotoran seperti, pasir dan tanah, kemudian dikeringkan dibawah sinar matahari. Tempurung kelapa yang bersih dimasukkan kedalam ball mill untuk dihaluskan menjadi partikel dengan ukuran 80 mesh. Plastik kemasan cup bekas dicuci dengan aquades lalu dikeringkan dipotong-potong dengan ukuran $\pm 1 \mathrm{~cm} \times 1 \mathrm{~cm}$.

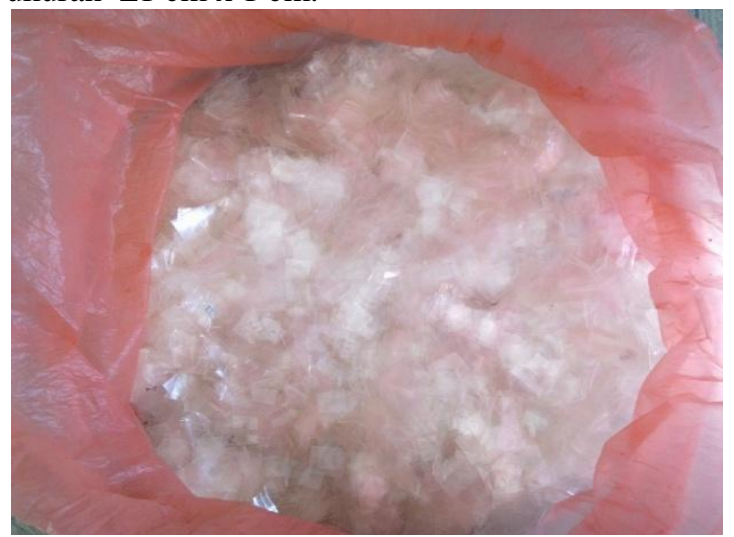

Gambar 1. termoplastik bekas berukuran $\pm 1 \mathrm{~cm}$

\section{Esterifikasi partikel Tempurung Kelapa}

Partikel tempurung kelapa dimodifikasi dengan larutan asam stearat $(0,3,6$, dan 9 gram asam stearat dilarutkan dengan $30 \mathrm{ml}$ etanol) selama satu jam.Partikel termodifikasi dicuci, dan dikeringkan didalam oven pada temperatur $70{ }^{\circ} \mathrm{C}$ selama satu jam.

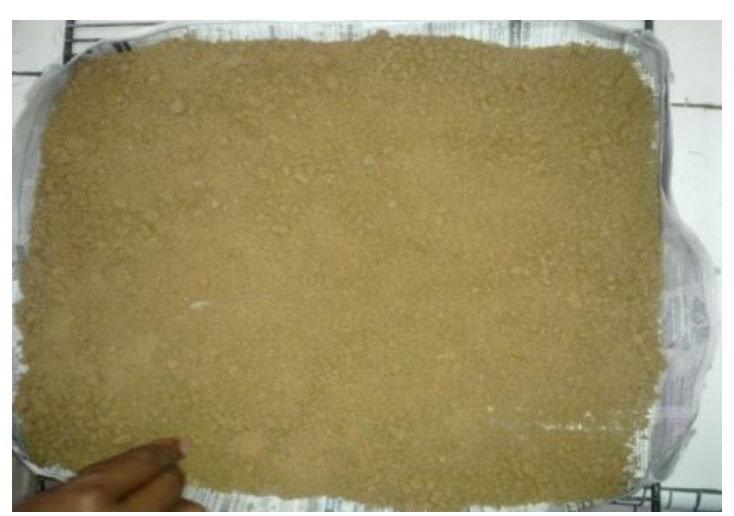

Gambar 2. Partikel tempurung kelapa termodifikasi

\section{Pembuatan papan partikel}

Termoplastik bekas/partikel tempurung kelapa termodifikasi (60:40) dimasukkan kedalam ekstruder pada temperatur $170^{\circ} \mathrm{C}$ sehingga terbentuk granular-granular, lalu dimasukkan kedalam alat pengempa panas untuk dicetak dengan spesimen pada temperatur $170^{\circ} \mathrm{C}$ selama 15 menit sehingga menjadi papan partikel dengan ukuran $200 \mathrm{~mm}$ x $200 \mathrm{~mm}$ x $10 \mathrm{~mm}$.

Tabel 1. Formulasi komposit termoplastik bekas/serbuk tempurung kelapa

\begin{tabular}{|l|l|}
\hline \multicolumn{1}{|c|}{ Bahan } & \multicolumn{1}{c|}{ Komposit } \\
\hline Termoplatik bekas (bps) & $60 \%$ \\
\hline Serbuk tempurung kelapa (bps) & $40 \%$ \\
\hline Asam stearat ( g) & $0,3,6,9$ \\
\hline Etanol (ml) & 60 \\
\hline
\end{tabular}

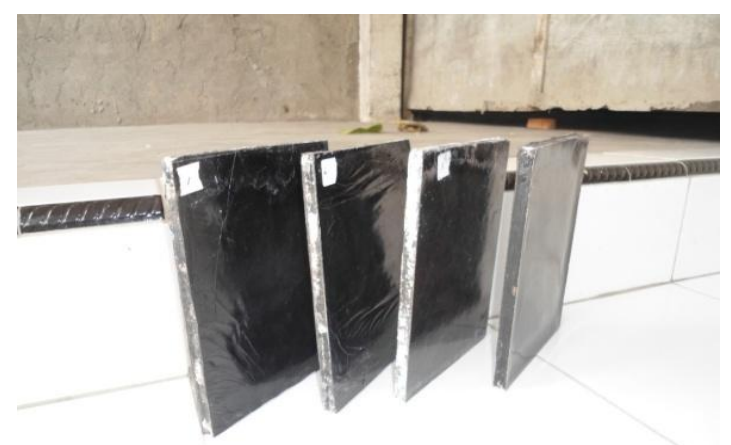

Gambar 3. Papan partikel termoplastik bekas berpengisi tempurung kelapa.

\section{Pengujian Papan partikel}

Papan partikel dengan ukuran $200 \mathrm{~mm}$ x 200 mm x 10 mm, diuji sifat Keteguhan Patah/Modulus of Rupture sesuai dengan SNI 03-2105-2006 dengan memakai alat servo control computer system universal testing machine model AI-7000 M Capacity 2000 kg, Power 1Ф 220 V 50 HZ. 


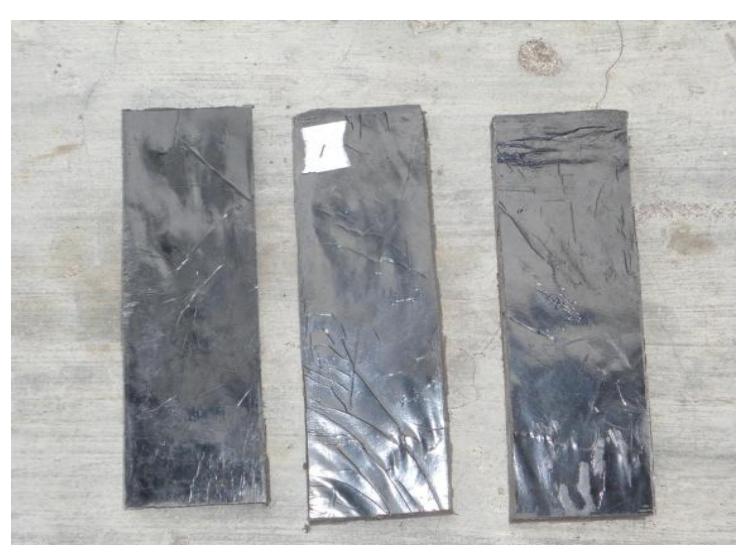

Gambar 4. Spesimen papan untuk pengujian kekuatan patah

\section{Hasil dan Pembahasan}

Pengaruh asam stearat terhadap sifat keteguhan patah/modulus of rupture papan partikel termoplastik bekas berpengisi tempurung kelapa (60/40) terlihat pada Gambar 5 di bawah ini.

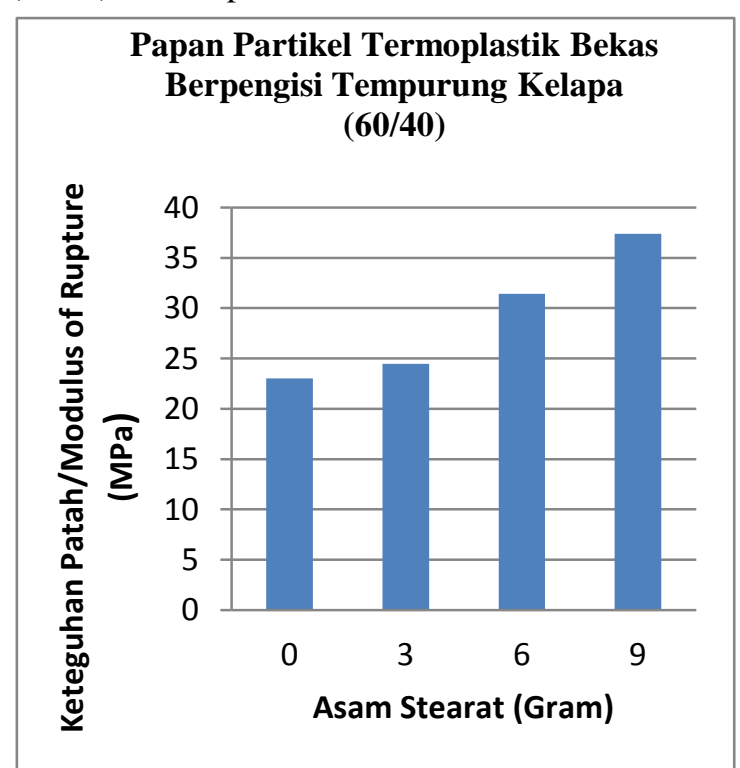

Gambar 5. Pengaruh asam stearat terhadap sifat keteguhan papan partikel termoplastik bekas berpengisi tempurung kelapa $(60 / 40)$

Dari Gambar 5 terlihat bahwa semakin banyak asam stearat yang digunakan sebagai penyerasi pada papan partikel termoplastik bekas berpengisi serbuk tempurung kelapa, sifat keteguhan patah/Modulus of Rupture semakin meningkat, sifat keteguhan patah/Modulus of Rupture terkecil pada tanpa modifikasi kimia (asam stearat $0 \mathrm{~g}$ ) sebesar 23,013 MPa dan yang terbesar pada asam stearat $9 \mathrm{~g}$ yaitu 37,402 $\mathrm{MPa}$. Peningkatan sifat keteguhan patah/Modulus of Rupture disebabkan oleh modifikasi pengisi partikel tempurung kelapa dengan penyerasi asam stearat, sehingga terjadi proses esterifikasi yang menyebabkan jumlah gugus - $\mathrm{OH}$ pada selulosa partikel tempurung kelapa yang bersifat hidrofilik menjadi berkurang. Dengan berkurangnya gugus - $\mathrm{OH}$, maka serbuk tempurung kelapa akan lebih bersifat hidrofobik sehingga akan meningkatkan ikatan antar muka pengisi dan matriks. Partikel tempurung kelapa memiliki kandungan lignin lebih tinggi dari selulosa [5]. Lignin berfungsi sebagai bahan pengkaku dan meningkatkan hidrofobitas pada molekul-molekul selulosa dalam dinding sel partikel organik. Kehadiran lignin yang bersifat non polar dalam partikel tempurung kelapa juga menambah kenon-polaran partikel yang telah dimodifikasi sehingga menyebabkan peningkatan adhesi antar muka di antara pengisi dan matriks (polietilena densitas rendah) yang bersifat non polar [1]. Mwaikambo dan Ansell (1999) menyebutkan bahwa modifikasi kimia juga bertujuan untuk menghilangkan senyawa-senyawa pengotor pada permukaan pengisi. Hal tersebut juga berpengaruh terhadap sifat mekanik dan reaksi pengikatan gugus hidroksil pada proses esterifikasi [11].

\section{Kesimpulan}

Asam stearat sebagai agen penghubung antara matriks (termoplastik bekas) dan pengisi tempurung kelapa dapat meningkatkan nilai sifat keteguhan patah/Modulus of Rupture sebesar $37,402 \mathrm{MPa}$

\section{Ucapan Terima Kasih.}

Penulis mengucapkan terima kasih kepada Reinaldi dan juga DP2M Dikti yang telah membiayai penelitian ini dalam Program Penelitian Hibah Bersaing Tahun 2013.

\section{Daftar Pustaka.}

[1] Anonim, Papan Partikel, SNI 03-2105-2006, Badan Standardisasi Nasional 2006 Jakarta .

[2] Febrianto, F, Komposit Kayu Plastik:Komposit Hijau untuk Bahan Bangunan Massa Depan : Tinjauan Teknik Bahan Baku, Proses, Sifat-Sifat, Penggunaan dan Pemasaran, Jurnal Teknologi Hasil Hutan, ISSN 0215-3351, Hal :102-114.2005, IPB

[3] Ferris, F, Sintetis Film Kemasan Ramah Lingkungan dari Komposit Pati, Khitosan dan Asam Polilaktat dengan Pemlastik Gliserol: Studi Morfologi dan Karakteristik Mekanik, Logika, Agustus 2008, ISSN 1410-2315, Hal. 13-18, 2008 
[4] Ginting, H, Kajian Awal Pembuatan Komposit Termoplastik Cup Berpengisi Serbuk Tempurung Kelapa dengan Penyerasi Asam Akrilat", Prosiding Seminar Nasional Teknik Kimia 2009 ISSN 1693881, Hal:108-115, 2009 Medan

[5] Ginting, H; Salmah; Halimatuddahliana; Tengku Hamid, Effec of Acrylic Acid on the Mechanical Properties of Coconut Shell Filled Low Density Polyethylene (LDPE) Composite, Proceedings The 1 ST Sustainable Technology Development (ICSTD) Bali 2010 ISBN 978-602-8566-964, Hal :C 44-C 4,2010 Universitas Udayana Bali

[6] Ginting, H, Pengaruh Asam Asetat Terhadap Peningkatan Sifat kekuatan Tarik Komposit Termoplastik Bekas Berpengisi Serbuk Kulit Salak, Buletin Ilmiah STTH ISSN 08535175, Hal:1-6, Edisi No 12, Oktober 2011, Medan

[7] Ginting, H, Pengaruh Maleat an Hidrat Terhadap Sifat Mekanik Komposit Termoplastik Bekas Berpengisi Serbuk Tempurung Kelapa", Buletin Ilmiah STTH ISSN 0853-5175, Edisi No 13, Maret 2011, Hal:58-63,2012 Medan

[8] Ginting H dan Rosdanelli, Pengaruh Asam Stearat Terhadap Sifat Kekuatan Tarik dan Pemanjangan Pada Saat Putus Komposit Termoplastik Bekas Berpengisi Serbuk Tempurung Kelapa, Prosiding Seminar Nasional Teknik Kimia Soebardjo Brotohardjono IX 2012 ISSN 1978-0427, 2012, UPN Surabaya.

[9] Hari wibowo,Toto Rusianto, Manarul Ihksan Pengaruh Kepadatan dan Ketebalan Terhadap Sifat Isolator Panas Papan Partikel Sekam Padi”, Jurnal Teknologi, 2008

[10] Kim, H, S;Lee, B, H; Choi, S, W dan Kim, $\mathrm{H}$, J,The Effect of types of maleic an Hydride Grafted Polypropylene (MAPP) on the Interfacial Adhesion Properties of Bioflour-Filled Polypropylene Composite, 38(A) : 1473-1482, 2009

[11] Mwaikambo, L,Y; dan Ansell, M. P, The effect of Chemical Treatment on The Properties of Hemp, Sisal, Jute, Kapok Fibres for Composite Reinforcement", $2^{\text {nd }}$ International Wood and Natural Fibre Composite Symposium, Kasell-Germany, 1999.
[12] Noor Mirad Sari, Sifat Fisik dan Mekanik Papan Partikel dari Limbah Plastik/Jenis HDPE (High Density Polyetyle) dan Ranting/Cabang Karet (Hevea brasiliensis Muell.Arg), Jurnal Riset Industri Hasil Hutan Vol 3.No 1 Juni 2011:7-14, 2011 Banjarbaru.

[13] Sudarsono, Toto Rusianto, Yogi Suryadi Pembuatan Papan Parikel Berbahan Baku Sabut Kelapa Dengan Bahan Pengikat Alami (Lem Kopal, Jurnal Teknologi, Volume 3 Nomor 1, Juni 2010 : 22-32, 2010 